\title{
A System Dynamic Model for Sustainable Construction and Demolition Waste Recycling in Libya
}

\author{
Itad Shiboub, PhD Candidate \\ Gabriel J. Assaf, Full Professor
}

École de Technologie Supérieure, Université du Québec, Rue Notre-Dame Ouest, Montréal, Québec, Canada

Doi: 10.19044/esj.2019.v15n6p191～URL:http://dx.doi.org/10.19044/esj.2019.v15n6p191

\begin{abstract}
In Libya, Construction and Demolition Waste materials (C\&DW) are currently thrown in landfills or illegally dumped. In regions where the C\&DW is not landfilled, insufficient C\&DW management fails to take advantage of the full value of the materials that could be repurposed for road construction. This research aims to develop a sustainable C\&DW management model appropriate to Libya and similar countries. Over $97 \%$ of construction in Libya uses cement; therefore, this study focuses on cement production and consumption and creates a simulation to model the parts of the construction industry. This study uses System Dynamics (SD), which is a tool used by stakeholders in policy planning to make better decisions about how to manage C\&DW. This study models and predicts C\&DW from 2008 until 2030, taking material cost, availability, recyclability and environmental, economic and social impacts into account. The model conforms to historical data from 2008 to 2016 and then becomes a predictive model until 2030; the years following 2011 are particularly critical due to the amount of destruction and the resulting rebuilding. The model shows that having a higher collection budget does not result in better environmental outcomes unless there is money allocated for $\mathrm{C} \& \mathrm{DW}$ recycling. The study quantifies the amount of material in Libya generated from demolition that is not reused; this data becomes a means of analyzing the value of the waste. The model output provides important data (e.g., cement consumption, GDP) for future resource management.
\end{abstract}

Keywords: Recycling, C\&DW, System-Dynamics-Modelling, Cementproduction, Road-Construction-Libya 


\section{Introduction}

Both developed and developing countries face the challenge of adequately managing natural resources in a way that improves the environmental, social, and economic development, or sustainable development (SusD) relating to Construction and Demolition Waste Materials $(\mathrm{C} \& D W)$. In this study, the focus is on a developing country where such C\&DW management has reached a crisis level, namely Libya, from where the data were collected. C\&DW in Libya is at a crisis level because Libya suffers from a lack of suitable materials for public works projects and road construction, for example, gravel and angular sand (Almadwi and Assaf, 2018). Transportation and depletion of these materials have enormous consequences on SusD. Also, there is a large amount of demolition material resulting from the current civil war in Libya that leads to waste. If the appropriate decision is not taken to deal with these materials, it will increase the current crisis. Instead of using recycled materials that could come from construction and demolition as well as from civil war, current projects are using virgin raw materials. This can lead to two consequences. The first is the clogging of disposal sites where the waste represents a liability for the environment. The second is the loss of the potential value of the waste material by not reusing it. To date, no one has looked at re-using the demolition material (from the civil war as well as other sources) for construction projects.

Issues about the environment, including landfill availability and natural habitat destruction (due to factors such as quarry excavation and landfills), have become important problems in need of policy solutions at the national level (Chakra \& Machaka, 2015). The objective is to establish and identify the essential elements of the SD model for C\&DW.

\section{General Issues}

Sustainability is one of the most important criteria when developing a framework for recycling C\&DW. C\&DW is the result of "activities such as the construction of buildings and civil infrastructure, total or partial demolition of buildings and civil infrastructure, road construction and maintenance" (Environment Commission, 2014). Infrastructure in society is an ongoing and growing societal need at the core of the well-being of the community but also one that generates a lot of waste. In essence and for practical purposes, most C\&DW consists of stone, brick, concrete, mortar, and asphalt; particularly in more recent construction, there are also materials such as glass, wood, metal, plastic, and contaminants such as silt, silicates, sulfate, chlorides, and organic materials (Di Maria, Bianconi, Micale, Baglioni, \& Marionni, 2016). What 
can, for instance, be easily controlled is what selection of materials are approved as being "sustainable." According to Waris, Shahir Liew, Khamidi, \& Idrus,(2014) this selection process may be the easiest means for a project to ensure sustainability in the implementation of construction projects.

Marzouk \& Azab (2014) claims that there is a still greater problem in developing countries such as Egypt. Here there are very large amounts of waste that need to be processed. At the moment, there are no systematic means of recycling it, and most waste is simply disposed of, either legally or illegally, and not processed or recycled. Such a situation will present serious economic concerns in the future. Currently, the money allocated to the problem is used to put the waste in a landfill and to minimize the problems associated with landfilling. All of this contributes to a growing sustainability problem, the details of which include: 1) the depletion of raw material; 2) the shrinking space available for landfills; 3) environmental damage; 4) increased energy consumption for new material manufacturing; 5) contamination from landfill leakage into the soil and off-gassing into the atmosphere.

Until the 1930s, in developed countries, the mechanism of material selection and decision-making and the objectives of construction were always to minimize the original cost of this construction. Since that period, there has been a growing awareness of the disadvantages of this approach because the objective of having a low cost for the initial project might conflict with the objective of having low ongoing operation and rehabilitation costs (Akadiri, 2011). For example, a building might be cheap to build but expensive to operate (e.g. to heat or cool). For this reason, there has been a shift in emphasis at the regulatory level in many countries; there is now a greater focus on the lifecycle costs of the entire project. Lifecycle Cost Analysis (LCCA) is, therefore, an important tool in the economics of construction projects, especially in the public sector of many countries.

Another equally important economic evaluation technique is Lifecycle Costing (LCC), which quantifies all costs such as increased safety, reduced emissions, and other usually non-tangible costs and benefits. LCC can thus be used for decision-making and is especially useful for choosing between different construction material options (Arpke \& Strong, 2006).

While LCCA is useful, it has to be multidimensional and to account for environmental and social effects due to the many factors that must be taken into consideration in the interface of human activities and the environment (Akadiri, 2011). It may also be difficult to balance out the concerns of all stakeholders. These sustainability issues must, therefore, include minimizing environmental, economic and social concerns. In order to address the concerns 
of all stakeholders, there are a number of factors that must be kept under control.

C\&DW is not easy to calculate and is easy to underestimate. For example, the 2012 C\&DW estimates for Europe (EU-28) were approximately 820 million tons per year. This represented about one-third of the total waste generated. In the US, the estimate was about 480 million tons. In India, with a population approximately three times the size of the US, it was approximately 530 million tons, according to 2013 estimates. The European Directive on waste (2008/98/EC, otherwise known as the "Waste Framework Directive") has set targets of at least $70 \%$ recycling and reuse of C\&DW by 2020 . In response to this, a great effort has been deployed towards C\&DW reduction, reuse, recycling, and management. This said, there is a general consensus that the main problems with regard to $\mathrm{C} \& \mathrm{DW}$ reduction are material quality and economic viability (Di Maria et al., 2016).

For instance, Finland currently falls short of the average Europeanrecycling target of $47 \%$; to create incentives for projects to recycle C\&DW, Finland, as of 2016, has restricted the disposal of waste in landfills. This new regulation may create more demand for other ways of using waste plastics and wood in particular (Dahlbo, Bachér, Lähtinen, ..., \& 2015, 2015).

Poon (2007) and Azad \& Zarmina (2015), discuss examples from areas in Hong Kong as well as in mainland China and Pakistan where they must account for the dramatic limitations on land availability. There, C\&DW has obstacles to aggregate reuse that are similar to those existing in other areas; these problems include: 1) the low cost of landfill disposal; 2) the absence of taxes on cheap virgin raw aggregate; 3 ) lack of progressive regulations on contractor requirements; 4) lack of education within the construction sector about the application of recycled aggregate.

Duran, Lenihan, \& O'regan (2006) outlines certain preconditions necessary before this situation changes. One precondition is that the cost of bringing C\&DW to a recycling centre should be cheaper than bringing the same C\&DW to a landfill. A second factor is that the costs of similar recycled materials become cheaper than raw virgin materials. For example, in roadwork, the cost of recycled aggregates should be cheaper than the cost of primary aggregates. These cost factors rely on the properties of the demolished materials and how they have been mechanically treated (Boateng, 2017 ; Huang, Lin, Chang, \& Lin, 2002 ; Tam \& Tam, 2006). For this purpose, studies confirm that such recycling is a reasonable substitute for natural raw virgin aggregates. These factors lower the market demand for recycled 
materials and limit the interest in businesses that might focus on such materials.

Renovation, construction, and demolition all produce C\&DW in varying amounts, regardless of the size of the project. C\&DW composition, quality and amount are not standard from site to site, region to region or even country to country (Dahlbo et al., 2015). For example, a Finnish study showed that, in 2007, there were about two million tons of C\&DW (non-hazardous) generated in the following stages: $16 \%$ construction; $57 \%$ demolition; $27 \%$ renovation (Dahlbo et al., 2015).

In recent years, there has been a large and noticeable expansion in building construction in Libya (Ngab, 2007). In addition, there are a great number of maintenance projects. So that they can be recycled in the future, the design and the selection of materials for any new construction both need to be of high quality. This expansion makes some stakeholders and authorities think about the objectives of the construction industry in sustainable ways. In Libya, the last decade has seen construction practices without suitable planning or promotion, and these projects are not sustainable construction environments (OECD, 2016). In order to create such environments, there must be initiatives to encourage or even regulate sustainable development (Ali \& Ezeah, 2017).

\section{Quality of Infrastructure in Libya}

Libya has geographic advantages with its position on the Mediterranean Sea and the need for Egypt and Tunisia to connect by land. Private sector development relies on everything from roads, ports, airports to telecommunications and the electrical grid. Such an infrastructure must be reliable for the regular delivery of goods and services to get to market. Without these, the competitiveness of the country's economy will suffer due to heightened transaction and trade costs. Before the 2011 revolution, Libya already had an infrastructure that had been deteriorating for years.

By 2010, decades of isolation and neglect placed the country in 115th place on a list of 139 countries on the Global Competitiveness Index (GCI) for its overall quality of infrastructure. The 2014 ranking put Libya in the last place, 144 out of 144; see Table 1. By this time, the road infrastructure had further deteriorated due to the ongoing conflict. Production levels and associated revenues had gone down. As of 2012, Libyan government officials projected that the US $\$ 40$ billion should be invested in transport infrastructure alone (OECD, 2016). 
Table 1: Deterioration of the road and electrical infrastructure (OECD, 2016)

\begin{tabular}{|c|c|c|c|c|c|c|}
\hline \multirow{2}{*}{$\begin{array}{l}\text { Indexes for } \\
\text { Organizational } \\
\text { Structures and } \\
\text { Facilities }\end{array}$} & \multicolumn{2}{|c|}{ GCI 2014-15 } & \multicolumn{2}{|c|}{ GCI 2013-14 } & \multicolumn{2}{|c|}{ GCI 2010-11 } \\
\hline & Value & Rank/144 & Value & Rank/144 & Value & Rank/144 \\
\hline $\begin{array}{l}\text { Total of the } \\
\text { infrastructure quality } \\
\text { (transportation) }\end{array}$ & 1.9 & 144 & 2.3 & 144 & 3.2 & 115 \\
\hline \multicolumn{7}{|c|}{ Transport Infrastructure } \\
\hline Road Quality & 2.1 & 142 & 2.5 & 134 & 3.1 & 97 \\
\hline $\begin{array}{l}\text { Port infrastructure } \\
\text { Quality (Out of 7) }\end{array}$ & 2.6 & 131 & 3.0 & 124 & 3.2 & 116 \\
\hline $\begin{array}{c}\text { Air transport } \\
\text { infrastructure (Out } \\
\text { of } 7)\end{array}$ & 2.4 & 139 & 2.9 & 136 & 2.9 & 133 \\
\hline
\end{tabular}

Additionally, where the level of sensitivity to reuse and knowledge about it are high, there are still other obstacles to sustainable development. To take national strategies for sustainability and implement them at the local, project level is not an easy task, as pointed out by Ding, Yi, Tam, \& Huang (2016).

In the future, the makeup of C\&DW may change because ageing structures will either need renovation or come to the end of their useful lives (Boateng, 2017). How these new factors will affect C\&DW composition is not known. Particular questions pertain to how these factors will affect targets or if substantial reforms to the system must be undertake (Shiboub \& Assaf, 2018).

Reasons against sustainable development could be that it will continue to be cheaper to find sources of raw materials and continue to be cheaper to dispose of waste in landfills. Some believe it is cheaper now and will always be cheaper to find new resources and to put waste in the landfill. Finally, there is the question of risk; many believe it is not worth being innovative when doing so risks failure and disgrace. This is common in many areas and is referred to as an institutional barrier against change.

\section{Cement consumption values in Libya}

This research is distinguished by how it introduces cement production and consumption modelling to construction.

As discussed by Ali, Ezeah, \& Khatib (2016), cement is essential to concrete production, and over $97 \%$ of construction in Libya uses cement. This 
is why from the beginning a statistical analysis of cement production must include estimates of the amount of concrete in C\&DW in present-day Libya. From this, the amount of cement that is imported into the country or produced domestically can be calculated; modelling the C\&DW also helps calculate the amount of cement used in construction in Libya. Once the model has been established, other construction materials can also be analyzed. These analyses are only possible due to the good quality of Libyan cement use records; because of Libya's unstable political situation, these analyses are the best means to evaluate C\&DW in Libya. Fieldwork is not currently possible. Furthermore, construction projects often suffer from a lack of quality data of the quantity and kind needed for research. As discussed in Shiboub \& Assaf (2018), an alternate means of qualifying this data is to compare them, using a per capita analysis, to countries with equivalent economic and social characteristics; in other words, countries that draw their main economic power from oil exports and those that share similar cultural factors.

Previously, Libya was viewed as having the highest cement consumption in the world per capita, with an average of approximately six million tons per year (Ali et al., 2016). Starting in 1992 and up until 2006, cement consumption rose markedly, going from approximately four million tons a year to approximately seven million tons a year; this rise was due to the great quantity of government development projects. Some projects had been started by the government to augment cement production in Libya, with a production target of approximately 13.5 million tons by 2010; at that time, Libya was producing around ten million tons each year (Ali et al., 2016). Because Libya needs more cement than it produces, it has imported cement from its neighbours, including Turkey, Tunisia, and Egypt (Ali et al., 2016). Before 2011, there were plans to increase the level of cement production to about 15 million tons, and the Libyan government had gone so far as to issue permits to a number of foreign corporations to compensate for the shortfalls in production (Shiboub \& Assaf, 2018).

The priority of this research is to develop a sustainable C\&DW management model appropriate to the economic, physical and social environment of Libya and similar countries. In order to reduce pressures on landfills and to decrease demand for waste removal, recycling the C\&DW materials is the best and most sustainable way forward.

\section{Methodology}

1. VENSIM PLE software is used in this study to create a system dynamics (SD) model. The advantage of the program is that it has a 
graphical user interface (GUI) which helps the user to design and to test the SD model.

2. This SD model is targeted at reproducing the Reference Behaviour Patterns (RBP) of the sector of road construction as it relates to buildings to be reused, recovered, and recycled into road construction base and subbase materials. After establishing good definitions for these, considerations of how community behaviour and policies affect the recycling objectives must be determined in order to shift the community to eliminating landfill waste.

3. The SD model aims at improving understanding of current community behaviour and will help develop strategies to change this behaviour.

4. The data, once aggregated, will ensure the usability of the model. All materials that can be recycled will be counted in a group. GDP average growth rates, as well as the portion of GDP that goes to cement production, will be used to determine user base totals; for the purposes of modelling, this base is considered to be as active as possible, within the scope of the available facilities. To the extent that this aggregation affects model results, it is presumed to be minimal; considering the scope of the project, the trade-off is likely reasonable.

\section{The Various Scenarios}

According to Shiboub \& Assaf (2018), building a model necessarily starts with GDP, growth rate of average GDP, and net change in average GDP. In this study, additional significant factors were added, e.g. population and population growth because these are the most reliable indicators for economic growth and the construction that accompanies it. GDP average growth rates and the fraction of GDP that goes to cement production are essential behavioural factors in the generation of waste, as illustrated in Figure 1 and shown in Equation 1.

$$
F_{\text {concret }}=P_{\text {concret }} *(1+\Delta G D P) *(1+\Delta \text { Population })
$$

Where:

$$
\begin{aligned}
& \boldsymbol{F}_{\text {concret }}=\text { Future production of concrete waste } \\
& \boldsymbol{P}_{\text {concret }}=\text { Present production of concrete waste }
\end{aligned}
$$




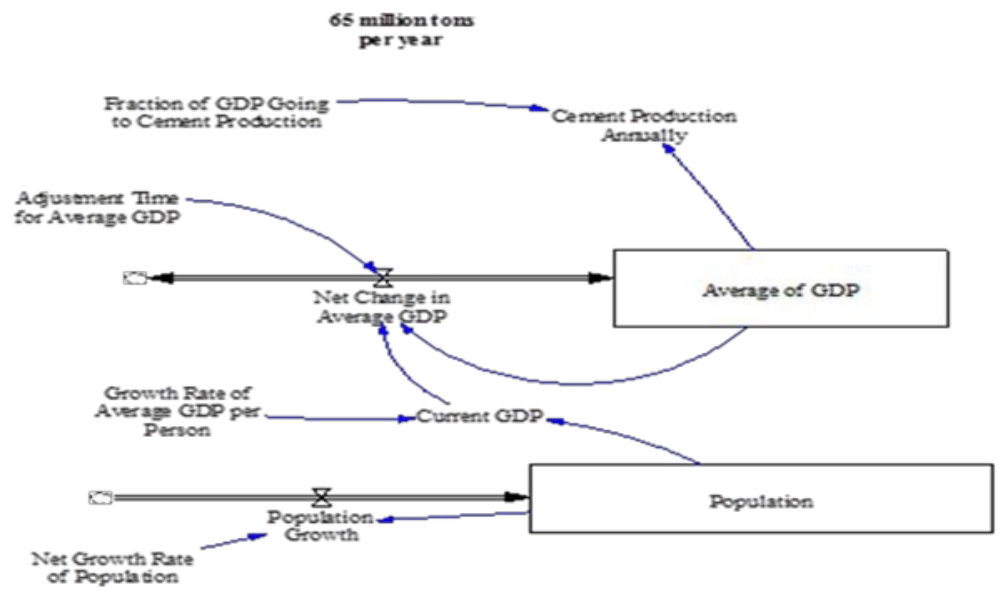

Figure 1. The model benchmark for C\&DW management and the flows and stocks with model factors

The time period for the simulation is from 2008 until 2030. This allows enough range for annual historical data to be used; for the years from 2008 until 2016, the simulation should match the recorded historical data, creating a baseline. The most important years in Libya are the years following the 2011 revolution because during this period many buildings were destroyed. Following this period, there were a lot of new growth projects. The last year that will be used for historical input data is 2016. From 2017 until the end of the simulation in 2030, the output data will be considered as a future projection; see Figure 2.

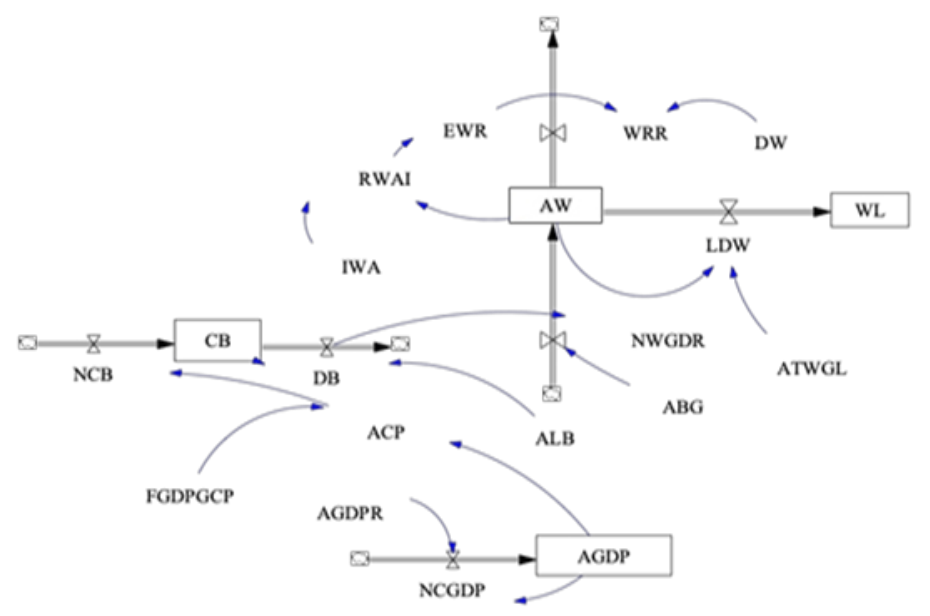

Figure 2. The model benchmark for C\&DW management and the flows and stocks with model factors 
In the model, the following internally determined factors are important: The Available Waste, GDP, Annual Cement Production, Landfill Designated Waste, Waste in Landfills, Cement in Buildings, Demolition of Buildings, New Construction of Buildings, Population and Population Growth, and Waste to Road Recycling, etc.; see Figures 1 and 2. Once these are known, a sustainable C\&DW recycling program can be developed. Both AW and LDW directly affect the WL. In the case where AW capacity is more than the LDW capacity, the AW rate equals the WL capacity; if not, it equals AW capacity. This is expressed in the following formula:

$$
A W=\text { if }(W L>L D W) \text { then } \rightarrow A W \rightarrow \text { else } \rightarrow(W L)
$$

Where: ${ }^{A W}$ : Available waste; ${ }^{W L}$ : Waste in landfills; ${ }^{L D W}$ : Landfill designated waste.

\begin{tabular}{|c|c|}
\hline 1. Annual Cement Production & $\mathbf{A C P}$ \\
\hline 2. Available Waste & $\mathbf{A W}$ \\
\hline 3. Average Building Generation & ABG \\
\hline 4. Average GDP & AGDP \\
\hline 5. Average GDP Growth Rate & AGDPGR \\
\hline 6. Average Life of Buildings & ALB \\
\hline 7. Average Time for Waste Going to Landfills & ATWGL \\
\hline 8. Cement in Buildings & CB \\
\hline 9. Demand for Waste & DW \\
\hline 10. Demolition of Buildings & DB \\
\hline 11. Effect of the Waste Ratio & EWR \\
\hline 12. Fraction of GDP Going to Cement Production & FGDPGCP \\
\hline 13. Initial Waste Available & IWA \\
\hline 14. Landfill Designated Waste & LDW \\
\hline 15. Net Change in Average GDP & NCAGDP \\
\hline 16. New Construction of Buildings & NCB \\
\hline 17. New Waste Generation From Different Resources & NWGDR \\
\hline 18. Ratio of Waste Available to Initial & RWAI \\
\hline 19. Waste in Landfills & WL \\
\hline 20. Waste to Roads Recycling & WRR \\
\hline
\end{tabular}




\section{Results and discussion}

The model benchmarks that have been created for C\&DW management are as follows. Annual Cement Production has similar results to Landfill-Designated Waste. This is also true of the flows and stocks that use factors from the model. Annual Cement Production has been regularly increasing over time, and it is an important indicator. These factors help stakeholders develop appropriate strategic plans for C\&DW recycling.

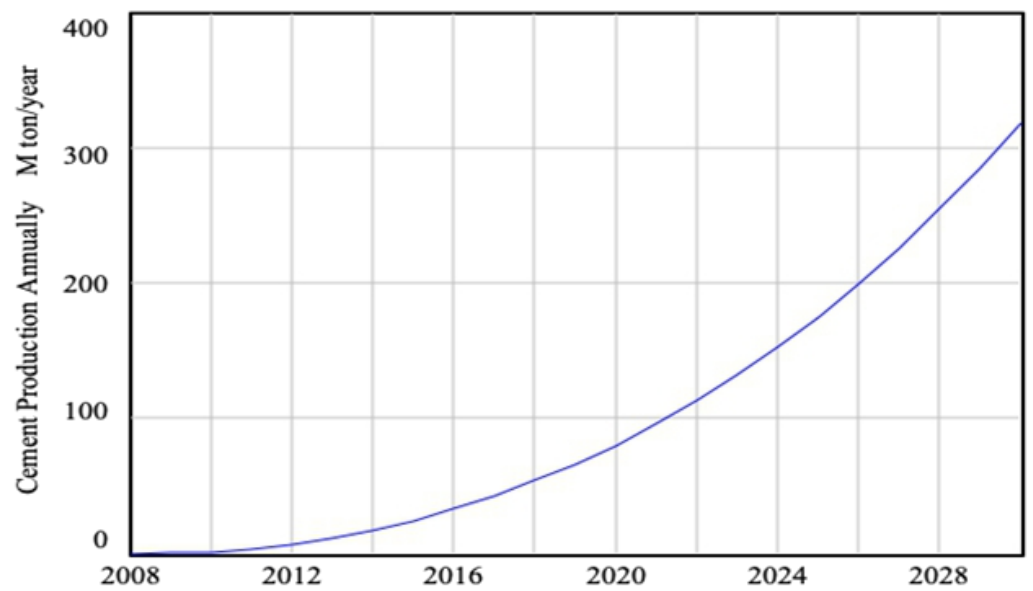

Figure 3: The Results, Annual Cement Production, interaction and simulation behaviours over time.

As Figure 3 in the middle of the simulation shows, 2020 for example, the annual production of cement will reach around 90 million tons; by the end of the simulation, in 2030 the annual production of cement in Libya is approximately 300 million tons due to the great amount of reconstruction and the new planning projects. The model takes into considering the projections for GDP growth, which is tied to the growth of the population; the population estimates for 2030 in the model are approximately 10 million as is illustrated in Figure 4. 


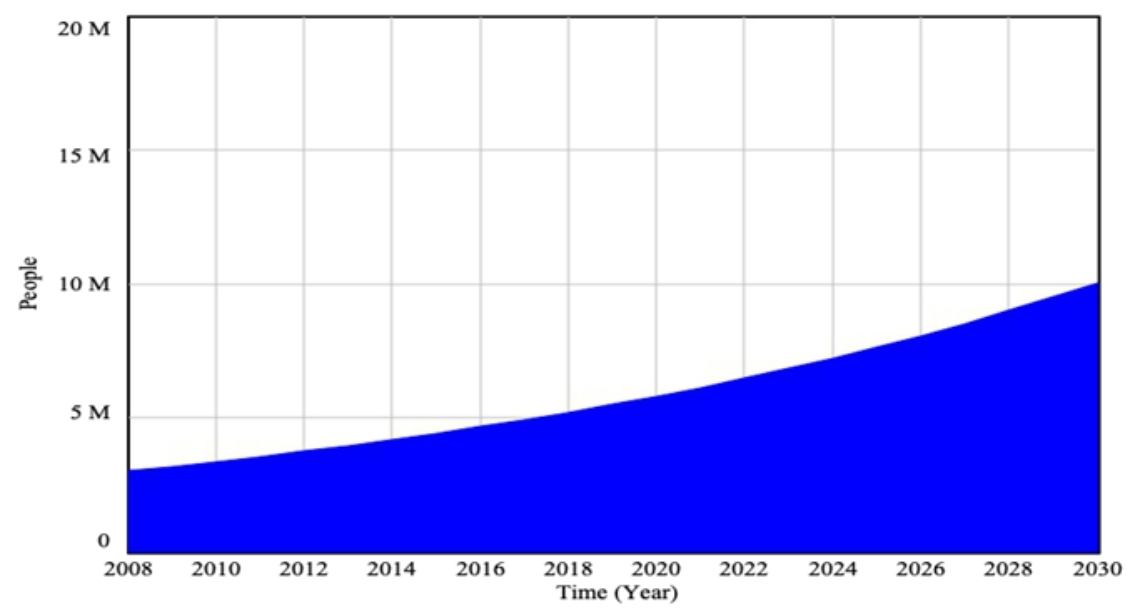

Figure 4: The Results, Current Population and Estimated Population in 2030. Net Change in Average GDP, Annual cement production, Cement in Building, New Construction of Building and Fraction of GDP Going to Cement Production all contribute to the Waste-toRoads Recycling rate.

The results in Figure 4 illustrate how the behaviour and the relationships between the factors in the model increase steadily over time; these factors are Available Waste, Average Building Generation, and Waste in Landfill. When the New Construction of Buildings variable is at a high rate, the Waste in Landfills rate increases, in this case, the overall Available Waste rate can appear to grow very quickly. Problems can arise when the C\&DW increases but the waste is not treated, as discussed. In these cases, the C\&DW is likely to be put in landfills instead of being reused or recovered. An attempted solution is to substitute natural aggregate, for example, with recycled aggregate from municipal waste; this substitution results in concrete that has no important difference in its compressive strength while resulting in a significant environmental benefit (Chakra \& Machaka, 2015). 


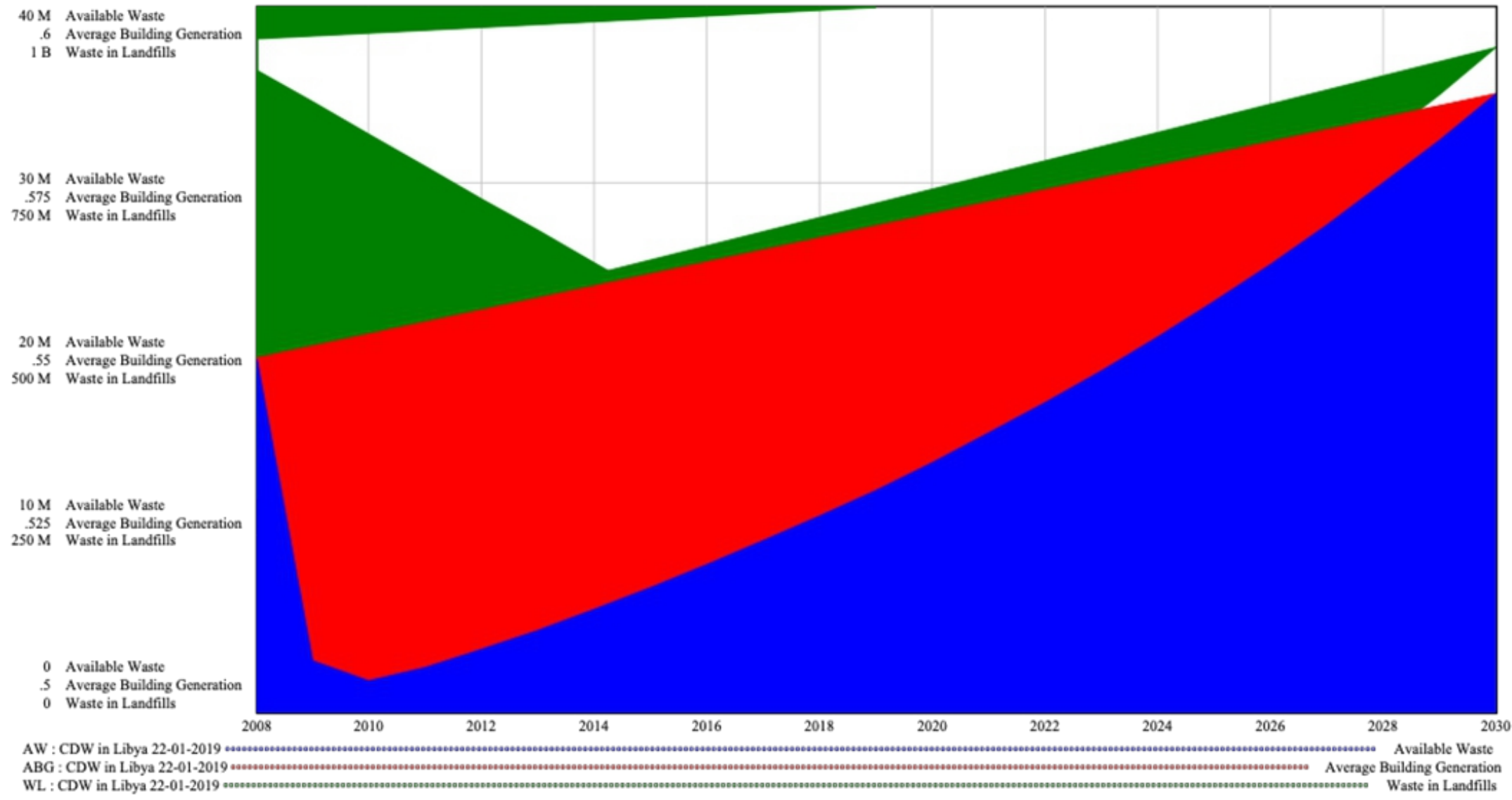

Figure 5. The results of the Available Waste (AW), Average Building Generation (ABG), and Waste in Landfills (WL) 
As shown in Figure 5, such programs usually grow exponentially in the beginning and then their growth levels off once some saturation is experienced in the system, in what is called a sigmoid or S-shaped growth curve; this can be compared with J-shaped growth, where the growth is very fast and then stops. However, they are typified, such a growth pattern needs to be avoided. Which is to say, often there is a pattern whereby the early adopters are receptive to the recycling program, and so the adoption of the recycling seems to grow in relation to the waste generation. Nonetheless, over time the recycling behaviour tends to level off and not keep pace with the waste generation.

WRR

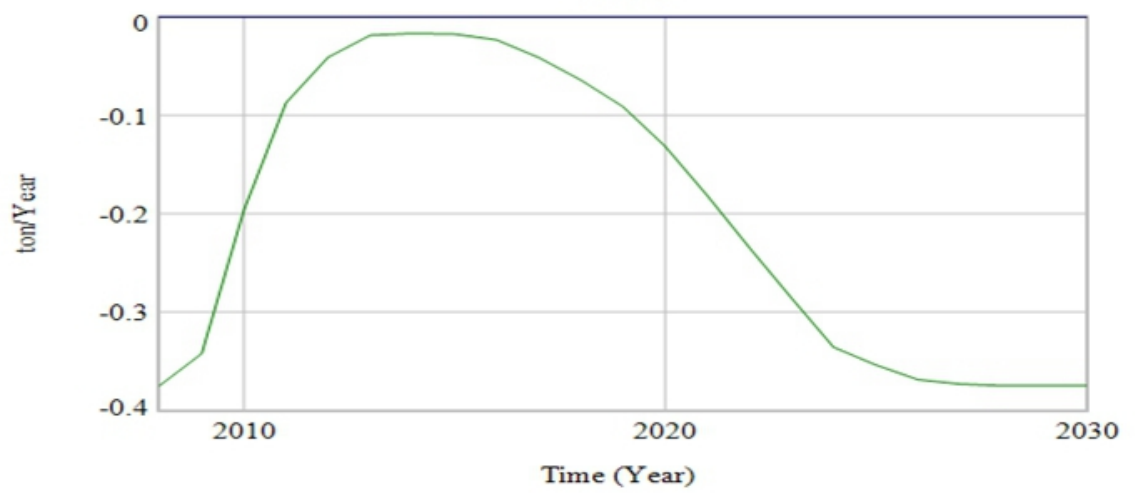

Figure 6. The relationship of the rate to Waste to Roads Recycling rate over time.

\section{Budget Allocation and Trucks Required}

The Collection Cost comes to $\$ 250$ per building, a cost also designed to influence the benchmarks in the model. Cost of $C \& D W$ is set at $\$ 300$, which is the per-building cost at which Effect of the Waste elements is given a high motivation to become the High Rate Waste to Road Recycling variable.

Figure 6 indicates the overall funding needed for C\&DW collection, landfilling and treatment over 25 years. 


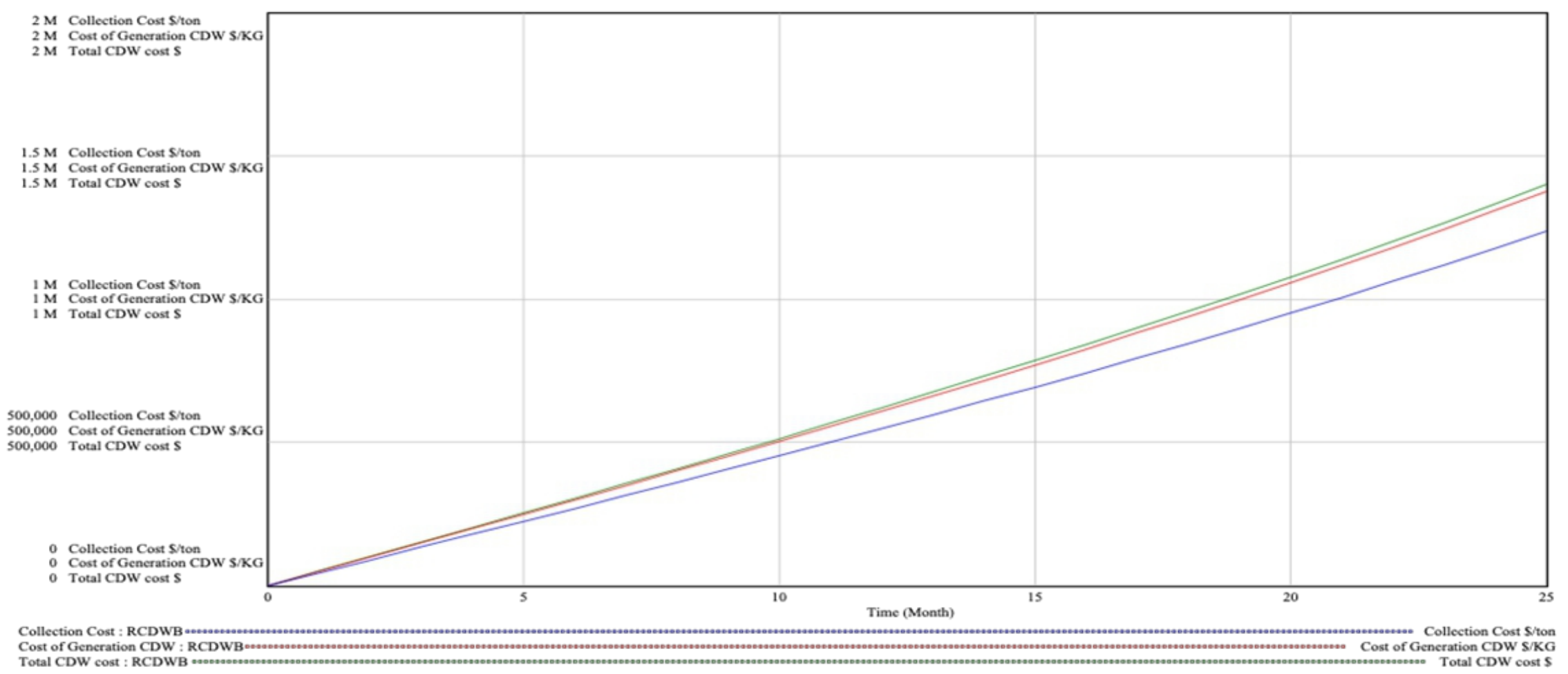

Figure 7. Simulated total C\&DW cost needed for important elements

The results in Figure 7 with the following elements illustrated: The Collection $C \& D W$ Cost dollar per ton, Cost of C\&DW Generation, and Total Cost (as a percentage of total) for 25 years of collections. The C\&DW Collection Cost in the total simulation increases over time because the overall number of C\&DW goes up; see Figure 4. 
Therefore, the required cost for C\&DW goes up to $\$ 500$ per ton from the initial years. According to these results, C\&DW processing Total costs go up for a period of 15 years and then the costs reach a relatively stable value of 1.5 million dollars due to how the use capacities of the processing centres are implemented. Note that in the same simulated period other costs also go up. These higher costs are because both the C\&DW processing capacity and the landfilling capacity approach their optimal maximum levels. According to calculations, the total costs go higher, while total costs for managing C\&DW also go up. As such, a higher financial investment is required to manage both the collection and the processing of C\&DW. Figure 7 illustrates the optimal quantity of trucks.

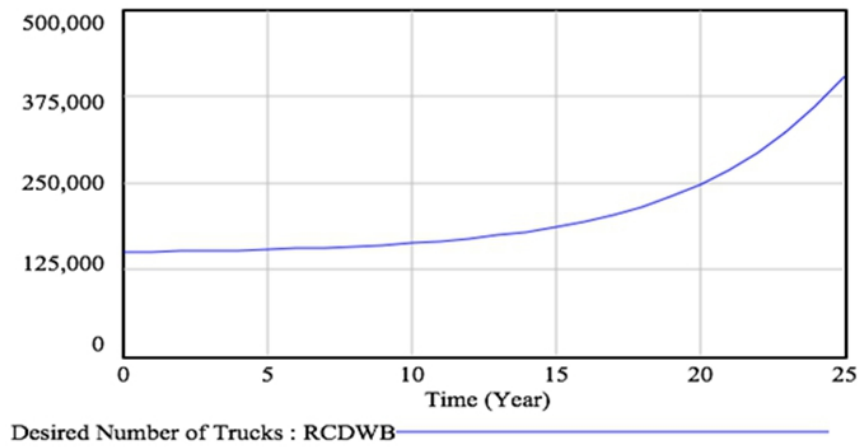

Figure 8. The optimal quantity of trucks per building per year

The total budget surpluses and deficits, the financial surpluses and deficits needed for C\&DW collection are simulated as a function of the percentage of available funds over 25 years. In the simulation, the optimal quantity of truck goes from 135 in the first ten years to 400 in the last year, while, over the same period, the recorded quantity of trucks goes from 125,000 in the first year to 450,000 by last year of the projection. This is to say that there is a notable difference between the optimal and actual quantity of trucks. Due to this difference, the quality of the C\&DW collection is getting worse, not better. Also, moving the C\&DW to the landfill is not well executed. C\&DW has been reported falling off of trucks during collection. C\&DW normally increases with the population because more buildings are constructed to house the greater population; as such, the optimal quantity of trucks increases. Therefore, there is a serious shortfall when it comes to a budget for C\&DW collection, especially with regard to trucks.

\section{- Verification and Validation}

Verification and validation become more straightforward as the model is developed due to how these constituents interact. They can be reduced to 
three categories, each including features of the validation methods that were used. In this research, validation depends on the three following elements: 1) ensuring that the model works according to plan and that the input data are correct; 2) verifying results with those from successful previous research (e.g. Bala, Arshad, \& Noh, 2017 ; Mashayekhi, 1993); 3) modelling a particular building, the details of which are below. The present research has completed the first two of these verification steps.

\section{Conclusion}

To address the problem of C\&DW materials being landfilled or, worse, illegally dumped in the outskirts of residential areas, it is critical that we understand the scope of C\&DW generation so that policy can be developed to address the problem. This paper has shown the preliminary results of an SD simulation model that incorporates historical C\&DW data to project future C\&DW generation over time. This model is tracked to such data as GDP and population growth as well as cement production and consumption. In the years covered, from 2008 until 2030, the model results that the C\&DW in Libya will grow from 500 million tons in 2008 to 1billion tons in 2030 as is shown in Figure 5. (This indicator includes a large amount of demolition material resulting from the current civil war in Libya that leads to the large of waste. Also because of the people who live outside the country and are expected to come back, as well as the people who are expected to immigrate to Libya in the future, such as workers for new companies, etc.) Policy initiatives are needed to ensure that this growth in C\&DW is directed to the right pathways, i.e., recycling and reuse so that the material could be repurposed to become base and subbase layers in roadway construction. Were it to be illegally dumped, it would result in the twofold problem described above, namely that there would be an unsustainable strain on virgin raw materials and at the same time a growing crisis in disposal with the known environmental, social, and economic impacts. The situation in Libya is stark because of the lack of governmental oversight at the local level and the absence of regulation at the national level. At the same time, the economy and population are both growing, despite the ongoing conflict, which itself is responsible for a great deal of C\&DW. This situation is not unique to Libya but is shared with countries such as Syria and Iraq and, not long ago, Lebanon. This is to say that the development of this simulation model as a tool for sustainable environmental, social and economic policy and eventually recycling centre development may, unfortunately, have wide use in countries that have experienced comparable social and historical events as Libya.

\section{References:}

1. Akadiri, O. P. (2011). Development of a Multi-Criteria Approach for 
the Selection of Sustainable Materials for Building Projects.

2. Ali, A., \& Ezeah, C. (2017). Framework for Management of PostConflict Waste in Libya. European Scientific Journal, 13(5), 32-49. https://doi.org/10.19044/esj.2017.v13n5p32

3. Ali, A., Ezeah, C., \& Khatib, J. (2016). Estimating Construction and Demolition (C\&D) Waste Arising in Libya. Philadelphia, PA U.S.A. : Solid Waste Technology and Management.

4. Almadwi and Assaf. (2018). Finding an Optimal Bitumen and Natural Sand Balance for Hot Mix Asphalt Concrete in Hot and Arid Regions. Dans Proceedings of the 5th GeoChina International Conference Civil Infrastructures Confronting Severe Weathers and Climate Changes in HangZhou, China (pp. 1-12). Springer, Cham.

5. Arpke, A., \& Strong, K. (2006). A comparison of life cycle cost analyses for a typical college dormitory using subsidized versus fullcost pricing of water. Ecological Economics. https://doi.org/10.1016/j.ecolecon.2005.05.019

6. Bala, B. K., Arshad, F. M., \& Noh, K. M. (2017). Stock and Flow Diagram. Dans System Dynamics (pp. 53-118). (S.1.) : (s.n.). https://doi.org/10.1007/978-981-10-2045-2_4

7. Boateng, P. (2017). Land Access, Agricultural Land Use Changes and Narratives about Land Degradation in the Savannahs of Northeast Ghana during the Pre-Colonial and Colonial Periods. Social Sciences, 6(1), 35. https://doi.org/10.3390/socsci6010035

8. Chakra, H. A., \& Machaka, M. (2015). Allocation Solutions for Recycled Municipalwaste Aggregates. European Scientific Journal, 11(26), 1857-7881.

9. Dahlbo, H., Bachér, J., Lähtinen, K., ... T. J.-J. of cleaner, \& 2015, U. (2015). Construction and demolition waste management-a holistic evaluation of environmental performance. Journal of Cleaner Production, 107, 333-341. Repéré à https://www.sciencedirect.com/science/article/pii/S09596526150019 85

10. Di Maria, F., Bianconi, F., Micale, C., Baglioni, S., \& Marionni, M. (2016). Quality assessment for recycling aggregates from construction and demolition waste: An image-based approach for particle size estimation. Waste

Management. https://doi.org/10.1016/j.wasman.2015.12.005

11. Ding, Z., Yi, G., Tam, V. W. Y., \& Huang, T. (2016). A system dynamics-based environmental performance simulation of construction waste reduction management in China. Waste Management. https://doi.org/10.1016/j.wasman.2016.03.001

12. Duran, X., Lenihan, H., \& O 'regan, B. (2006). A model for assessing 
the economic viability of construction and demolition waste recycling - the case of Ireland. Resources, Conservation and Recycling, 46 , 302-320. https://doi.org/10.1016/j.resconrec.2005.08.003

13. Environment Commission, E. (2014). Construction and demolition waste - Environment European Commission.

14. Huang, W. L., Lin, D. H., Chang, N. Bin, \& Lin, K. S. (2002). Recycling of construction and demolition waste via a mechanical sorting process. Resources, Conservation and Recycling, 37(1), 23-37. https://doi.org/10.1016/S0921-3449(02)00053-8

15. Marzouk, M., \& Azab, S. (2014). Environmental and economic impact assessment of construction and demolition waste disposal using system dynamics. Resources, Conservation and Recycling, 82, 41-49. https://doi.org/10.1016/j.resconrec.2013.10.015

16. Mashayekhi, A. N. (1993). Transition in the New York State solid waste system: A dynamic analysis. System Dynamics Review, 9(1), 23-47. https://doi.org/10.1002/sdr.4260090103

17. Ngab, A. S. (2007). Libya - the Construction Industry - an Overview (pp. 201-209). Karachi, Pakistan : CBM-CI International Workshop.

18. OECD. (2016). SMEs in Libya's Reconstruction: Preparing for a PostConflict Economy, The Development Dimension. Paris.

19. Poon, C. S. (2007). Management of construction and demolition waste. Waste management (New York, N.Y.), 27(2), 159-160. https://doi.org/10.1016/j.wasman.2006.10.012

20. Salahuddin, Azad., Zarmina, A. (2015). The Implementation in Construction of Sustainable Buildings in Pakistan. European Scientific Journal, 11(29), 369-379.

21. Shiboub, I., \& Assaf, G. J. (2018). Development of a Recycling System Policy for Construction and Demolition Waste Materials with Applications in Libya towards Sustainable Development. Dans International Conference of the System Dynamics Society - Reykjavík, Iceland Tuesday, August 7, 2018 (p. 7). Iceland. Repéré à http://proceedings.systemdynamics.org/2018/proceed/papers/P2336.p df

22. Tam, V. W. Y., \& Tam, C. M. (2006). A review on the viable technology for construction waste recycling. Resources, Conservation and Recycling, 47(3), 209-221. https://doi.org/10.1016/j.resconrec.2005.12.002

23. Waris, M., Shahir Liew, M., Khamidi, M. F., \& Idrus, A. (2014). Criteria for the selection of sustainable onsite construction equipment. International Journal of Sustainable Built Environment, 3(1), 96-110. https://doi.org/10.1016/j.ijsbe.2014.06.002 